\section{Safety and Effectiveness of Nalmefene vs. Naloxore in Opioid and Mixed Drug Overdose in the Prehospital Care Setting}

\author{
*Eric A. Davis, MD, James Menegazzi, PhD, \\ Andrew Sucov, MD \\ Division of Emergency Medicine, University of Pittsburgh \\ School of Medicine, Pittsburgh, Pennsylvania
}

Purpose: A new opioid antagonist, nalmefene $(\mathrm{NF})$, has a significantly longer half-life ( 8 hours) than does naloxone (NX). The purpose of this study was to evaluate the safety and efficacy of equipotent doses of nalmefene and naloxone in reversing opioid overdose in the prehospital setting.

Methods: This was a prospective, double blind, randomized, parallel group clinical trial from February to October 1991 utilizing an urban ALS-EMS system and three tertiary-care hospitals. Males over 18 years of age with altered mental status and suspected opioid use were eligible. Patients were assigned to receive NF or NX with subsequent administration based on patient response; those with inadequate response were eligible for NX rescue after four study doses. Patients were observed for four hours with respiratory rate, Neurobehavioral Assessment Scale (NAS), Glasgow Coma Scale Score (GCS), pupil size, Clinical Global Impression Scale, dosing, and rescue treatment were recorded. Subgroup analysis was based on opioid positives (OP) and initial respiratory status.

Results: There were no demographic or adverse event differences. Data were analyzed with a repeated measures ANOVA. and Tukey multiple comparisons (alpha $>0.05)$.

$\begin{array}{lcccccc} & \text { NX } & \text { OP NX } & \text { GCS } & \text { OP GCS } & \text { NAS } & \text { OP NAS } \\ & \text { Rescue } & \text { Rescue } & \text { DO-1 } & \text { DO- } 1 & 10 \mathrm{~min} & 10 \mathrm{~min} \\ \text { NF } & 11 / 35 & 4 / 11 & 20 / 32 & 4 / 9 & 10.7 & 9.7 \\ \text { NX } & 5 / 32 & 2 / 13 & 13 / 29 & 1 / 12 & 12.1 & 8.8 \\ p \text {-value } & .109 & .239 & .130 & .08 & .92 & .75\end{array}$

In comparing changes in opioid positive respiratory rate, there was a significant difference between groups at five $\min (p=0.03)$, but not at $10 \mathrm{~min}(p=0.8 \mathrm{l})$. Both drugs resulted in clinical improvement; this occurred more rapidly with NX.

Conclusion: Nalmefene capably reverses the effects of opioid induced altered mental status as compared to naloxone, however, the significant differences in respiratory improvement at 5 minutes may limit its prehospital use.

\section{Performance of Police First Responders Trained in the use of a Automated External Defibrillator}

\author{
*Eric A. Davis, MD, Vincent N. Mosesso, Jr., MD, \\ Curt Neill, EMT-P, Raymond E. Carlin, BS, \\ EMT-P, Mary Ann Scott, RN, BSN, EMT-P \\ Division of Emergency Medicine, University of Pittsburgh \\ School of Medicine, Pittsburgh, Pennsylvania
}

Purpose: The purpose of this study was to evaluate the performance of first responder police officers in the use of an automated external defibrillator (AED) after completing a 4.5-hour training program and to compare it to EMT-AED.

Methods: A one-group, time series design from February 1992 to November 1993 was utilized. Seven suburban police departments, that routinely respond to medical emergencies, were included. One-hundred-ninety police officers certified in first-aid and CPR were trained. All passed initial and quarterly practical exams. Performance was evaluated by: 1) written exam prior to, posttraining, and at six months; 2) assessment by on-scene ALS providers; and 3) author review of AED audio and rhythm tape utilizing preset criteria and compared to published EMT-AED rates. Data were analyzed with the one sample, exact binomial test; alpha was set at 0.05 .

Results: Average scores for the three tests were $69 \%$, $53 \%$, and $88 \%$ respectively. Ninety-two cases form the group for the analysis, with 33 shockable rhythms. Proportions for the study group's performance are presented with $95 \%$ confidence intervals (CI).

\begin{tabular}{|c|c|c|c|c|}
\hline Factor & $\begin{array}{c}\text { EMT AED } \\
n(\%)\end{array}$ & $\begin{array}{c}\text { Police AED } \\
n(\%)\end{array}$ & $95 \% \mathrm{Cl}$ & p-value \\
\hline $\begin{array}{l}\text { Correct } \\
\text { sequence }\end{array}$ & $93 / 273(34)$ & $85 / 92 \quad(92.3)$ & $.85-97$ & $<0.0000001$ \\
\hline No error rate & $95 / 273(35)$ & $51 / 87 \quad(58.6)$ & $.48-.69$ & 0.000006 \\
\hline CPR delay & $96 / 273(35)$ & $18 / 87 \quad(20.7)$ & $.13-.31$ & 0.03 \\
\hline $\begin{array}{l}\text { Failure } \\
\text { to clear }\end{array}$ & $63 / 273(23)$ & $0 / 33$ & $.0-.9$ & 0.0002 \\
\hline $\begin{array}{l}\text { Failure to } \\
\text { re-analyze } \\
\text { post-shock }\end{array}$ & $25 / 273(9)$ & (6.1) & $.1-.20$ & 0.42 \\
\hline
\end{tabular}

Police errors most often involved airway (16.1\%) and appropriate extra reanalysis $(19.6 \%)$. In no case did an officer fail to follow an AED prompt.

Conclusion: Police officers can properly utilize AEDs and compare favorably to EMTs. Future training strategies should stress accuracy and proper integration of CPR. 